\title{
PHYTOCHEMICAL ANALYSIS AND ANTIBACTERIAL ACTIVITY OF ERYNGIUM PYRAMIDALE BOISS. \& HAUSSKN
}

\author{
MOHAMMAD NEJATI ${ }^{a}$, SHIVA MASOUDI $^{a^{*}}$, DARA DASTAN $^{b}$ AND NASRIN MASNABADI $^{c}$ \\ ${ }^{a}$ Department of Chemistry, Central Tehran Branch, Islamic Azad University, Tehran, Iran. \\ ${ }^{b}$ Department of Pharmacognosy, School of Pharmacy, Medicinal Plants and Natural Products Research Center, Hamadan University of Medical Sciences, \\ Hamadan, Iran. \\ ${ }^{c}$ Department of Chemistry, Roudehen Branch, Islamic Azad University, Roudehen, Iran.
}

\begin{abstract}
Eryngium pyramidale Boiss. \& Hausskn. is one of the species of the Apiaceae family, which is used as a spice in Iranian food. In this work, we aim to assess the phytochemical profile and antibacterial activity of the aerial parts of Eryngium pyramidale. The essential oil was obtained by hydrodistillation using a Clevenger apparatus. Then, it was quantitatively and qualitatively analyzed by GC-FID and GC-MS, respectively. The antibacterial activity of the essential oil was evaluated against six gram-positive and three gram-negative bacteria by the disc diffusion method and the broth microdilution assay. The phenolic and flavonoid contents of the methanolic extract were assessed using the UV spectrophotometry and HPLC-DAD. A total of 56 compounds representing $94.08 \%$ of the total oil were identified, among which sesquicineole $(28.49 \pm 1.2 \%)$ and $(\mathrm{Z})$-falcarinol $(18.04 \pm 0.7 \%)$ were the major ones. Based on the results, the oil was active against both gram-positive and gram-negative bacteria in comparison with standards. The phytochemical screening of the extracts revealed the presence of flavonoids, steroids, glycosides, and phenols in the methanolic, ethyl acetate, and $n$-hexane extracts. The total phenolic content of the methanolic extract was $0.36 \pm 0.01 \mathrm{mg}$ of gallic acid equivalents per $\mathrm{g}$ of dry plant materials, and the total flavonoid content of the methanolic extract was $0.90 \pm 0.05 \mathrm{mg}$ of quercetin equivalent (QE) per gram of dry plant materials. Five phenolic and flavonoid compounds in the methanolic extract including naringenin, rutin, apigenin, caffeic acid, and gallic acid were identified and quantified.
\end{abstract}

Keywords: Antibacterial, Eryngium Pyramidale Boiss. \& Hausskn., Essential oil, Flavonoids, Phenolics, Phytochemical screening.

\section{INTRODUCTION}

The genus Eryngium has been found to be the largest genus in the family Apiaceae (Umbelliferae) and consists of around 300 species, which are dispersed in the temperate areas of every continent, mostly in Eurasia, North Africa, and South America [1,2]. Nevertheless, the east and west parts of the world indicate unequal species richness; North, Central, and South America have approximately two-thirds of Eryngium species [3, 4]. Also, ten species of the genus Eryngium are distributed in Iran in different environmental conditions such as temperate and semi-arid areas $[5,6]$.

Various species of the genus Eryngium like other Apiaceae family members have been reported to possess ornamental, culinary, agricultural, and medicinal applications. Moreover, many Eryngium species have been widely employed in folk medicine as hypoglycemic, antitussive, poison antidote, kidney stone inhibitor, stimulant, diuretic, aphrodisiac, and anti-inflammatory agents [7-9]. On the other hand, Eryngium species demonstrate a wide variety of biological and pharmacological activities such as antibacterial, antitumor, antifungal, antiinflammatory, anti-snake and scorpion venoms, antimalarial, antioxidant, and antihyperglycemic activities $[9,10]$ due to having a considerable amount of secondary metabolites and biologically active chemical compounds such as polyacetylenes [11, 12], coumarins [13, 14], flavonoids [14], phenolics [15, 16], terpenoids [17, 18], triterpenoid saponins [19], and steroids [20, 21].

The essential oils and extracts of different species of the genus Eryngium have been shown to have antibacterial effects against various infectious diseases [22]. Eryngium pyramidale is a medicinal plant from the Apiaceae family that is applied as a spice in Iranian food by local people. In previous study by Fallahzadeh et al. the analgesic and anti-inflammatory effect of Eryngium pyramidale essential oil was reported [23]. In this study, we aim to determine the chemical composition of the essential oil obtained by hydrodistillation from the aerial parts of Eryngium Pyramidale Boiss. \& Hausskn using gas chromatography-flame ionization detection (GC-FID) and gas chromatography/mass spectrometry (GC/MS) and investigate the antibacterial activity of the essential oil against both gram-positive and gram-negative bacteria using the disc diffusion method and the broth microdilution assay. Furthermore, this study aims to evaluate the phenolic and flavonoid contents of the methanolic extract by the UV spectrophotometry and HPLC-DAD.

\section{EXPERIMENTAL}

\subsection{Plant material}

The aerial parts of Eryngium pyramidale Boiss. \& Hausskn. were harvested from Kurdistan province of Iran during the flowering season in July 2018. The plant was identified by a botanist (Hiva Ghaderi), and then a voucher specimen (406) was deposited in the Herbarium of the School of Pharmacy, Hamadan University of Medical Sciences, Hamadan, Iran.

\subsection{Essential oil preparation}

In order to isolate the essential oil of the aerial parts of Eryngium pyramidale, the air-dried and finely ground aerial parts of the plant $(170 \mathrm{~g})$ were submitted to hydrodistillation with a Clevenger-type apparatus for $3 \mathrm{~h}$. Then, the oil was collected and dried over anhydrous sodium sulfate, and finally, the yellowish colored oil was obtained in the yield of $0.4 \%$ (w/w).

\subsection{GC and GC-MS analyses}

Gas chromatography-flame ionization detection (GC-FID) and gas chromatography-mass spectrometry (GC-MS) analyses were used to identify the components of the essential oil both quantitatively and qualitatively. The GCFID analysis was carried out on a gas chromatograph (Thermoquest-Finnigan, UK) equipped with a split/splitless injector $\left(250{ }^{\circ} \mathrm{C}\right)$ and a flame ionization detector (FID) $\left(300{ }^{0} \mathrm{C}\right)$. Nitrogen was utilized as carrier gas $(1 \mathrm{ml} / \mathrm{min})$, and the capillary column applied for the analysis was a DB-5 fused-silica column (J \& W Scientific, USA: $60 \mathrm{~m} \times 0.25 \mathrm{~mm}$, film thickness $0.25 \mu \mathrm{m}$ ). The column initial temperature was $60{ }^{\circ} \mathrm{C}$ and then increased to $250{ }^{\circ} \mathrm{C}$ at a rate of $5{ }^{\circ} \mathrm{C} / \mathrm{min}$ and maintained for $2 \mathrm{~min}$. The isolated oil was diluted in $\mathrm{n}$-hexane 1:4 v/v, and $1 \mu \mathrm{l}$ of the solution was injected into the GC-FID apparatus with a split ratio of 1:50.

The GC-MS analysis was accomplished using a Thermoquest-Finnigan GC to a TRACE mass spectrometer (Manchester, UK) with a J \& W Scientific column, USA: $60 \mathrm{~m} \times 0.25 \mathrm{~mm}$, film thickness $0.25 \mu \mathrm{m}$ ). The same methods for the GCFID analysis were applied to the temperature program of the column, sample preparation, sample injection amount, and sample injection conditions. The flow rate of the mobile phase (helium) was $1.1 \mathrm{ml} / \mathrm{min}$, and the mass spectra were recorded at the ionization energy of $70 \mathrm{eV}$. Furthermore, the mass scan range was from 43 to $456 \mathrm{~m} / \mathrm{x}$.

\subsection{Identification and quantification of volatile compounds of the essential oil}

Based on the Van den Dool method, the GC retention indices for the components of the essential oil were defined in order to identify the compounds, applying n-alkanes $\left(\mathrm{C}_{6}-\mathrm{C}_{30}\right)$ as standards [24]. The compounds were identified by the comparison of their retention indices with those previously published in the literature and also by the comparison of their mass spectral data with the Adams library and the published mass spectra [25]. In order to quantify the components of the essential oil, relative area percentages achieved by GC-FID 
were employed without the use of correction factors. The analysis was repeated three independent times, and the mean values were reported.

\subsection{Extract preparation}

To prepare the extracts, the air-dried aerial parts of $E$. pyramidale were finely ground into powder form using a mechanical grinder. Then, the powder $(50 \mathrm{~g})$ was separately added to $500 \mathrm{ml}$ methanol, $500 \mathrm{ml}$ of ethyl acetate, and $500 \mathrm{ml}$ of $n$-hexane solutions for $72 \mathrm{~h}$ at room temperature. The extracts were filtered through a Whatman filter paper and then concentrated under reduced pressure at $40{ }^{\circ} \mathrm{C}$ with a rotary evaporator (Heidolph, Germany) to gain solvent-free extracts. The solvent-free extracted residues were stored in the dark in a freezer until further analyses.

\subsection{Phytochemical screening}

The preliminary phytochemical analyses of the methanolic, ethyl acetate, and $n$-hexane extracts were done based on the standard procedures $[26,27]$ so as to identify various secondary metabolites such as proteins, flavonoids, tannins, amino acids, phlobatannins, steroids, terpenoids, glycosides, anthraquinones, phenols, alkaloids, and saponins.

\subsection{Determination of total phenolic (TPC) and total (TFC) flavonoid contents}

The Folin-Ciocalteu method was applied to assess the total phenolic content (TPC) of the plant extracts. Gallic acid (3,4,5-trihydroxybenzoic acid) was also used as the reference compound. The amount of $20 \mu \mathrm{l}$ of each sample extract (10 $\mathrm{mg} / \mathrm{ml}$ ) was mixed with $500 \mu \mathrm{l}$ of the Folin-Ciocalteu reagent and $2 \mathrm{ml}$ of distilled water. Then, the mixture was incubated at room temperature for $3 \mathrm{~min}$. After that, $300 \mu \mathrm{l}$ of sodium carbonate solution (7\%) was added to the mixture and was incubated in the dark with occasional shaking for $30 \mathrm{~min}$. Then, the absorbance of the mixture was recorded at the wavelength of $765 \mathrm{~nm}$ against a blank reagent using a Synergy HDX ELISA reader, and finally, linear calibration curves (absorbance versus concentration) were plotted for different concentrations. The total phenolic content values of the extracts were calculated based on the standard curve equation $(\mathrm{R} 2=0.99)$ and expressed as milligrams of gallic acid equivalents per $\mathrm{g}$ of dry plant materials [28].

The total flavonoid content (TFC) of the plant extracts was evaluated using aluminum chloride $\left(\mathrm{AlCl}_{3}\right)$ as a reagent and quercetin as a standard reference according to the method described by Kerdar et al. [28]. The amount $0.2 \mathrm{ml}$ of $\mathrm{AlCl}_{3}$ reagent $(10 \%, \mathrm{w} / \mathrm{w})$ was mixed with $0.6 \mathrm{ml}$ of ethanol $(30 \%, \mathrm{v} / \mathrm{v}), 0.2 \mathrm{ml}$ of $\mathrm{NaNO}_{2}(1 \mathrm{M})$, and $0.2 \mathrm{ml}$ of each extract $(10 \mathrm{mg} / \mathrm{ml})$. Then, the mixture volume was diluted to $2 \mathrm{ml}$ using distilled water. The final mixture was incubated at room temperature for $60 \mathrm{~min}$. After that, the absorbance of the mixture was recorded at the wavelength of $415 \mathrm{~nm}$ with a Synergy HDX ELISA reader. Different dilutions of the standard solution of the quercetin were prepared in ethanol, and their absorbance was read at $415 \mathrm{~nm}$. The standard calibration curves of the absorbance and concentration were then plotted. Using the standard curve equation $(\mathrm{R} 2=0.99)$, the total flavonoid content values of the extracts were determined, which were expressed as milligrams of quercetin equivalent $(\mathrm{QE})$ per gram of dry plant materials.

\subsection{Antibacterial activity}

The disc diffusion method on Mueller-Hinton agar medium by measuring inhibitory zone diameters and the broth microdilution assay by determining minimal inhibitory concentration (MIC) values were applied so as to evaluate the antibacterial activity of the essential oil obtained from the aerial parts of Eryngium pyramidale against 6 gram-positive and 3 gram-negative bacteria according to the methods reported by Baron and Finegold [29].

The 6 standard strains of gram-positive bacteria included Staphylococcus aureus (ATCC 25923) (American Type Culture Collection); Staphylococcus epidermidis (ATCC 12228), Bacillus subtilis (ATCC 465), Bacillus cereus (PTCC 1015) (Persian Type Culture Collection), Bacillus pumilus (PTCC 1274), and Enterococcus faecalis (ATCC 29737); and the 3 standard strains of gramnegative bacteria included Klebsiella pneumoniae (ATCC 10031), Escherichia coli (ATCC 25922) and Pseudomonas aeruginosa (ATCC 85327). The standard antibiotics used as a positive control for bacteria were ampicillin (10 mg/disc), tetracycline (30 mg/disc), and gentamicin (10 mg/disc). The inhibition zone diameter (IZ) was recorded in $\mathrm{mm}$, including a $6 \mathrm{~mm}$ diameter of the paper disc, with a caliper after a $24-\mathrm{h}$ incubation at $37^{\circ} \mathrm{C}$. Based on the broth microdilution method, the MIC values $(\mathrm{mg} / \mathrm{ml})$ of the essential oil were measured, which were defined as the lowest sample concentration that inhibited the bacterial growth after incubation for $24 \mathrm{~h}$ at $37^{\circ} \mathrm{C}$.

\subsection{HPLC analysis of the phenolic compounds}

The standard phenolic compounds including quercetin, rutin, trans-resveratrol, gallic acid, (+)-catechin, benzoic acid, caffeic acid, ferulic acid, apigenin, and naringenin; which were purchased from Sigma-Aldrich Corporation (St. Louis, MO, USA); were employed for the HPLC analysis. Different concentrations of the standard compounds were separately measured and then injected into the HPLC apparatus. For each phenolic standard, a standard calibration curve was produced by plotting the area of peaks against different concentrations of the phenolic and flavonoid compounds. The calibration curves obtained from the standards were used to determine the amounts of the phenolic compounds in the methanolic extract, which were expressed as $\mathrm{mg} / 100 \mathrm{~g}$ of the plant. The identification and quantitative analyses of the phenolic compounds were performed by the comparison of the chromatograms of the methanolic extract with those of the standard compounds.

In order to evaluate the phenolic and flavonoid compounds in the methanolic extract, the HPLC analyses of the methanolic extract and the standards were conducted using the reversed-phase high-performance liquid chromatography (RP-HPLC-DAD) (Shimadzu Scientific Instruments, Kyoto, Japan) equipped with a photodiode array detector (SPD-M20A), auto-sampler (SIL-20AC), autoinjector (SIL-10ADvp), a dual solvent pump (LC-20AD), and a C18 reversedphase column $(25 \mathrm{~cm} \times 4.6 \mathrm{~mm}, 3 \mu \mathrm{m})$ at $25^{\circ} \mathrm{C}$. The solvent A (the water-acetic acid mixture, 97:3, v/v) and solvent B (HPLC grade methanol, Merck, Germany) constituted the mobile phases. The flow rate of the mobile phases was $1 \mathrm{ml} / \mathrm{min}$, and the spectral data from all peaks were recorded in the wavelength range of 200-400 $\mathrm{nm}$. The injection volumes were $20 \mu \mathrm{l}$ of the sample extract and the standard compounds. The gradient elution program used was as follows: $0.0 \mathrm{~min}$, $0 \%$ B; 0-10 min, $20 \%$ B; $10-30$ min, $20-50 \%$ B; 30-55 min, $50-100 \%$ B; $55-65$ $\min , 100 \% \mathrm{~B}$. The amount of run time for each sample analysis was $65 \mathrm{~min}$

\section{RESULTS AND DISCUSSION}

\subsection{Chemical compositions of the essential oil}

The identification and quantification of the components of the essential oil obtained from the aerial parts of Eryngium pyramidale were carried out by GCMS and GC-FID, respectively (Table 1 and Figure 1). Table 1 presents the chemical composition of the essential oil, the relative retention indices, the relative retention indices in the literature, and the content percentages of the components in the essential oil. According to the results in Table 1, approximately $94.08 \%$ of all components in the essential oil of E. pyramidale were identified, which included 48 compounds. As can be seen in Table 1 and Figure 2, the two chief constituents of the obtained essential oil were sesquicineole $(28.49 \pm 1.2 \%)$ and $(\mathrm{Z})$-falcarinol $(18.04 \pm 0.7 \%)$; whereas, spathulenol $(10.21 \pm 0.7 \%)$, $\alpha$-bisabolol (4.74 $\pm 0.1 \%)$, 14-hydroxy-(Z)caryophyllene $(3.77 \pm 0.2 \%)$, 3-butylhexahydrophthalide $(3.48 \pm 0.5 \%), \beta$ gurjunene $(3.41 \pm 0.03 \%)$, octanal $(3.01 \pm 0.08 \%)$, and callitrin $(3.01 \pm 0.4 \%)$ were obtained from the essential oil as the other considerable components. On the other hand, the obtained essential oil comprised oxygenated diterpene $(0.10 \%)$, monoterpene hydrocarbon $(0.74 \%)$, oxygenated sesquiterpene $(54.81 \%)$, sesquiterpene hydrocarbon $(4.89 \%)$, and non-terpenoid $(33.54 \%)$ compounds. It can be concluded from these results that sesquiterpenes predominated over monoterpenes and non-terpenoid compounds in the essential oil of E. pyramidale.

The chemical compositions of the essential oils obtained from many Eryngium species have already been investigated. In most of the studied Eryngium species (American, Australian, and European), sesquiterpenes were found to be the main compounds in the essential oils. Nonetheless, germacrene D, $\alpha$-pinene, caryophyllene, $\alpha$ - and $\beta$-selinene, limonene, $\alpha$ - and $\beta$-bisabolol and muurolene have been shown the most common monoterpenes in different parts of Eryngium species $[22,30]$. In this study, the results indicated that sesquiterpenes such as sesquicineole and spathulenol were the main compounds in the essential oil of $E$. pyramidale. Overall these findings are in accordance with most of the findings reported by previous studies on Eryngium species. 
Table 1. Percentage composition of the essential oil obtained from Eryngium pyramidale.

\begin{tabular}{|c|c|c|c|c|c|}
\hline & Components $^{[\mathrm{a}]}$ & $\mathbf{R I}^{[\mathbf{b}]}$ & $\%\left( \pm \mathbf{S D}^{[\mathrm{c}]}\right)$ & $\mathbf{R I}^{[\mathbf{d}]}$ & RT \\
\hline 1 & Heptanal & 901 & $0.25 \pm 0.01$ & 901 & 3.55 \\
\hline 2 & $\alpha$-Pinene $e^{[\mathrm{e}]}$ & 932 & $0.13 \pm 0.01$ & 932 & 4.10 \\
\hline 3 & 6-Methyl-5-Hepten-2-one & 989 & {$[\mathrm{t}]$} & 989 & 4.97 \\
\hline 4 & Octanal & 998 & $3.01 \pm 0.08$ & 998 & 5.29 \\
\hline 5 & $p$-Cymene & 1024 & $0.14 \pm 0.01$ & 1022 & 5.77 \\
\hline 6 & 2-Nonanone & 1090 & $1.01 \pm 0.01$ & 1087 & 7.23 \\
\hline 7 & (z)-6-Nonenal & 1103 & $0.60 \pm 0.03$ & 1097 & 7.52 \\
\hline 8 & (E)-2-Nonenal & 1159 & $0.31 \pm 0.02$ & 1157 & 8.89 \\
\hline 9 & 1-Decen-3-ol & 1182 & $0.24 \pm 0.02$ & 1177 & 9.45 \\
\hline 10 & Decanal & 1206 & $0.10 \pm 0.0$ & 1201 & 10.04 \\
\hline 11 & (E,E)-2,4-nonadienal & 1219 & $0.10 \pm 0.0$ & 1210 & 10.39 \\
\hline 12 & (E)-2-Decenal & 1261 & $0.13 \pm 0.01$ & 1260 & 11.50 \\
\hline 13 & 2-Undecanone & 1295 & $0.11 \pm 0.0$ & 1293 & 12.38 \\
\hline 14 & (E)-2-Undecenal & 1363 & {$[\mathrm{t}]$} & 1357 & 14.10 \\
\hline 15 & $\rho$-Menth-1-en-9-ol acetate & 1428 & $0.83 \pm 0.07$ & 1421 & 15.72 \\
\hline 16 & $\beta$-Gurjunene & 1435 & $3.41 \pm 0.03$ & 1431 & 15.90 \\
\hline 17 & 6-9-Guaiadiene & 1442 & $0.12 \pm 0.0$ & 1442 & 16.06 \\
\hline 18 & Allo-Aromadendrene & 1463 & $0.10 \pm 0.0$ & 1458 & 16.58 \\
\hline 19 & Dodecanol & 1471 & $0.10 \pm 0.0$ & 1469 & 16.78 \\
\hline 20 & Ar-Curcumene & 1484 & $0.39 \pm 0.02$ & 1479 & 17.08 \\
\hline 21 & Pentadecane & 1488 & $0.42 \pm 0.03$ & 1500 & 17.18 \\
\hline 22 & $(\mathrm{Z})$ - $\alpha$-Bisabolene & 1502 & $0.30 \pm 0.01$ & 1506 & 17.52 \\
\hline 23 & Sesquicineole & 1521 & $28.49 \pm 1.2$ & 1515 & 17.97 \\
\hline 24 & cis-Sesquisabinene hydrate & 1544 & $0.10 \pm 0.0$ & 1542 & 18.52 \\
\hline 25 & Silphiperfol-5-en-3-ol A & 1555 & $0.62 \pm 0.05$ & 1557 & 18.78 \\
\hline 26 & (E)-2-Tridecenal & 1564 & $0.44 \pm 0.05$ & 1567 & 18.99 \\
\hline 27 & Spathulenol & 1585 & $10.21 \pm 0.7$ & 1577 & 19.46 \\
\hline 28 & 1-Hexadecene & 1589 & $0.87 \pm 0.07$ & 1588 & 19.57 \\
\hline 29 & Globulol & 1597 & $0.13 \pm 0.0$ & 1590 & 19.75 \\
\hline 30 & Hexadecane & 1601 & $0.35 \pm 0.01$ & 1600 & 19.84 \\
\hline 31 & $\beta$-Atlantol & 1608 & $0.52 \pm 0.03$ & 1608 & 20.00 \\
\hline 32 & (E)-2-Decenal & 1618 & $0.20 \pm 0.0$ & 1618 & 20.22 \\
\hline 33 & 3-Butylhexahydrophthalide & 1626 & $3.48 \pm 0.5$ & 1632 & 20.41 \\
\hline 34 & cis-Cadin-4-en-7-ol & 1637 & $0.20 \pm 0.04$ & 1635 & 20.65 \\
\hline 35 & 1,2-Dihydro-8-hydroxy Linalool & 1643 & $0.20 \pm 0.01$ & 1654 & 20.77 \\
\hline 36 & $\alpha$-Bisabolol oxide $\mathrm{B}$ & 1651 & {$[\mathrm{t}]$} & 1656 & 20.96 \\
\hline 37 & (z)-Falcarinol & 1659 & $2.61 \pm 0.09$ & 1662 & 21.14 \\
\hline 38 & 14-Hydroxy-(Z)-caryophyllene & 1663 & $3.77 \pm 0.2$ & 1666 & 21.23 \\
\hline 39 & 14-Hydroxy-9-epi-(E)-Caryophyllene & 1669 & $0.35 \pm 0.05$ & 1668 & 21.37 \\
\hline 40 & Germacra-4(15),5,10(14)-trien-1 $\alpha$-ol & 1677 & $0.49 \pm 0.04$ & 1685 & 21.53 \\
\hline 41 & $\alpha$-Bisabolol & 1687 & $4.74 \pm 0.1$ & 1685 & 21.77 \\
\hline 42 & Acorenone & 1697 & $0.13 \pm 0.01$ & 1697 & 21.98 \\
\hline 43 & 14-Hydroxy-4,5-dihydro- $\beta$ - Caryophyllene & 1716 & $0.56 \pm 0.06$ & 1706 & 22.39 \\
\hline 45 & Cyptomerione & 1725 & $0.32 \pm 0.05$ & 1724 & 22.59 \\
\hline 46 & (Z)-Sesquilavandulyl acetate & 1732 & $0.18 \pm 0.0$ & 1732 & 22.74 \\
\hline 47 & $\alpha$-Bisabolol oxide $\mathrm{A}$ & 1741 & $0.31 \pm 0.02$ & 1748 & 22.92 \\
\hline 48 & (Z)-Lanceol & 1752 & $0.10 \pm 0.0$ & 1760 & 23.17 \\
\hline 49 & $\beta$-Bisabolenal & 1768 & $0.57 \pm 0.03$ & 1768 & 23.51 \\
\hline 50 & Pentadecanol & 1776 & $0.14 \pm 0.01$ & 1773 & 23.67 \\
\hline 51 & Callitrin & 1798 & $3.01 \pm 0.4$ & 1803 & 24.15 \\
\hline 52 & 2- $\alpha$-acetoxy-Amorpha-4,7(11)-diene & 1805 & $0.15 \pm 0.08$ & 1805 & 24.29 \\
\hline 53 & Flourensadiol & 1868 & $0.15 \pm 0.06$ & 1869 & 25.57 \\
\hline 54 & Hexadecanoic acid & 1974 & $0.61 \pm 0.1$ & 19595 & 26.62 \\
\hline 55 & (Z)-Falcarinol & 2045 & $18.04 \pm 0.7$ & 2035 & 28.96 \\
\hline \multirow[t]{7}{*}{56} & Incensole & 2143 & $0.10 \pm 0.02$ & 2158 & 30.74 \\
\hline & Monoterpene hydrocarbons & & 0.74 & & \\
\hline & Sesquiterpene hydrocarbons & & 4.89 & & \\
\hline & Oxygenated sesquiterpenes & & 54.81 & & \\
\hline & Oxygenated diterpene & & 0.10 & & \\
\hline & Other compounds & & 33.54 & & \\
\hline & Total & & 94.08 & & \\
\hline
\end{tabular}

[a]: Compounds are listed in order of elution from DB-5 MS column; $\mathrm{RI}^{[\mathrm{b}]}$ : Retention indices to $\mathrm{C}_{6}-\mathrm{C}_{30} \mathrm{n}$-alkanes on DB-5MS column; [c]: Standard deviation for three replications; $\mathrm{RI}^{[\mathrm{d}]}$ : Retention indices according to the literature $[\mathrm{t}]$ : trace $(<0.1 \%)$; [e]: The identification was also confirmed by co-injection with the standard. 


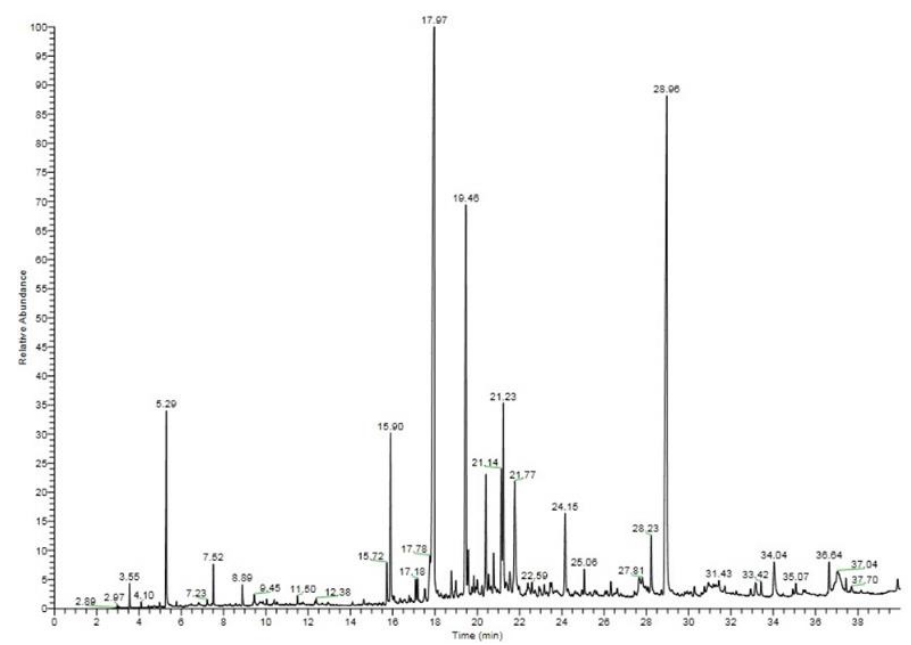

Figure 1. GC-MS chromatogram of the essential oil of the aerial parts of Eryngium pyramidale.

\subsection{Qualitative phytochemical analysis}

The presence of different secondary metabolites including flavonoids, steroids, terpenoids, glycosides, and phenols in the methanolic, ethyl acetate, and $n$ hexane plant extracts was established by the results obtained from the phytochemical analyses (Table 2). Based on the results in Table 2, the presence of flavonoids, steroids, and phenols was detected in all methanolic, ethyl acetate, and $n$-hexane extracts of Eryngium pyramidale. Among these compounds, flavonoids and phenols were mainly found in the ethyl acetate and methanolic extracts; while, steroids were moderately present in the three extracts. However, terpenoids were abundantly observed in the ethyl acetate extract. On the other hand, glycosides were only detected in the methanolic extract. On the contrary, proteins, tannins, amino acids, phlobatannins, anthraquinones, alkaloids, and saponins were not identified in all extracts. Interestingly, all extracts of $E$. pyramidale showed the absence of saponins, although the presence of these compounds has been observed in most of the Eryngium species.

Table 2. Qualitative phytochemical analysis of the extracts of Eryngium pyramidale.

\begin{tabular}{|l|l|l|l|}
\hline \multicolumn{1}{|c|}{$\begin{array}{c}\text { Phytochemical } \\
\text { Constituents }\end{array}$} & \multicolumn{1}{|c|}{$\begin{array}{c}\text { Methanolic } \\
\text { extract }\end{array}$} & $\begin{array}{c}\text { Ethyl acetate } \\
\text { extract }\end{array}$ & $\begin{array}{c}\text { n-Hexane } \\
\text { extract }\end{array}$ \\
\hline Proteins & - & - & - \\
\hline Flavonoids & +++ & +++ & + \\
\hline Tannins & - & - & - \\
\hline Amino acids & - & - & - \\
\hline Phlobatannins & - & - & - \\
\hline Steroids & ++ & ++ & ++ \\
\hline Terpenoids & - & +++ & + \\
\hline Glycosides & ++ & - & - \\
\hline Anthraquinones & - & - & - \\
\hline Phenols & +++ & +++ & + \\
\hline Alkaloids & - & - & - \\
\hline Saponins & - & - & - \\
\hline
\end{tabular}

$[+++]$ : Abundantly present, $[++]$ : Moderately present, [+]: Slightly present, []: Absent.

\subsection{Determination of the total phenolic and flavonoid contents}

Among various bioactive phytochemicals in medicinal plants that improve human health; both phenolic and flavonoid compounds are reported to show a wide range of biological effects such as antibacterial, anti-cancer, antioxidant, and anti-inflammatory activities; which make them receive so much attention in pharmaceutical, food, and cosmetic industries [31-34]. In this investigation, the total flavonoid content of the methanolic extract was $0.90 \pm 0.05 \mathrm{mg}$ of quercetin equivalent $(\mathrm{QE})$ per gram of dry plant materials, which was measured by the standard quercetin, the aluminum chloride reagent, and the standard curve equation. Furthermore, the amount of $0.36 \pm 0.01 \mathrm{mg}$ of gallic acid equivalents per $g$ of dry plant materials was obtained for the total phenolic content of the methanolic extract, which was calculated by the Folin-Ciocalteu reagent, the standard gallic acid solution, and the standard curve equation.

There have been many studies on the determination of the total phenolic and flavonoid contents of Eryngium species in recent years. For instance, Zeidan et al. conducted a study in 2015 to determine the antioxidant activity and the total phenolic and flavonoid contents of Eryngium creticum. In this study, the plant extracts were obtained using both conventional and non-conventional extraction techniques. Based on the results, the plant extract showed the highest TPC and TFC values for the microwave-assisted extraction technique [35]. In another study in 2020, Paşayeva et al. revealed that the ethyl acetate extract of $E$. kotschyi showed the highest total phenolic $(173.710 \pm 1.088 \mathrm{mg}$ gallic acid equivalent $/ \mathrm{g}$ extract) and total flavonoid contents $(86.978 \pm 0.650 \mathrm{mg}$ catechin equivalent/g extract), as well as indicating the highest antioxidant activity against the DPPH radical [36].

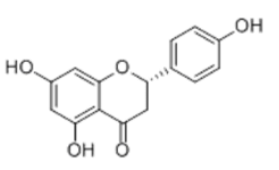

Naringenin<smiles>O=C(O)c1cc(O)c(O)c(O)c1</smiles>

Gallic acid<smiles>O=c1cc(-c2ccc(O)cc2)oc2cc(O)cc(O)c12</smiles>

Apigenin<smiles>O=C(O)/C=C/c1ccc(O)c(O)c1</smiles>

Caffeic acid
A

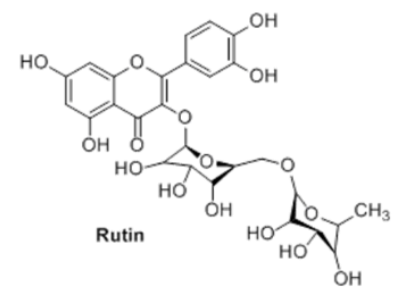

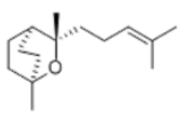

Sesquicineole

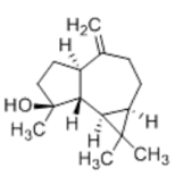

Spathulenol

\section{B}

Figure 2. Chemical structure of the major compounds in the methanolic extract (A) and the essential oil (B) of Eryngium pyramidale.

\subsection{Antibacterial activity}

In this work, the antibacterial activity of the essential oil obtained from the aerial parts of E. pyramidale was evaluated against three species of gramnegative and six species of gram-positive bacteria using the disk diffusion assay and the broth microdilution method (Table 3). The results in Table 3 revealed that the essential oil exhibited a significant inhibitory effect on the bacterial strains of Bacillus pumilus, Staphylococcus aureus, and Staphylococcus epidermidis with the growth inhibition zone diameters of $18 \mathrm{~mm}$ and the minimum inhibitory concentrations of $7.5 \mathrm{mg} / \mathrm{ml}$. The oil also indicated a noteworthy antibacterial effect against Escherichia coli with the growth inhibition zone diameter of $17 \mathrm{~mm}$ and the same minimum inhibitory concentration. Nevertheless, the growth of the other bacterial strains was moderately inhibited by the essential oil.

From the results of this study, it is clear that the growth of both gram-positive and gram-negative bacterial strains can be inhibited by the essential oil of the aerial parts of E. pyramidale. Overall these findings are in accordance with 
findings reported by previous studies, in which different positive biological activities, especially antibacterial effects, of the essential oils in this genus have been proven. For example, in a study conducted by Merghache et al., the antibacterial and antifungal activities of the essential oil obtained from the aerial parts of Eryngium tricuspidatum were evaluated against eleven bacterial strains and two fungal species by the micro-well dilution method. Based on the results, the essential oil showed major antibacterial effects on Staphylococcus aureus, Enterococcus faecalis, Pseudomonas aeruginosa bacterial strains with the MIC values of $9 \mu \mathrm{g} / \mathrm{mL}$ and Bacillus cereus, Listeria monocytogenes, Escherichia coli, Proteus mirabilis, and Klebsiella pneumoniae bacterial cultures with the MIC values of $18 \mu \mathrm{g} / \mathrm{mL}$. It also inhibited the growth of Candida albicans ATCC 10231 and Candida albicans ATCC 26790 fungal strains with the MIC values of $4.6 \mu \mathrm{g} / \mathrm{mL}$ [37]. In another study by Mirahmadi et al. in 2020, the disk diffusion and microdilution methods were used to assess the antibacterial activity of the essential oil of Eryngium caeruleum. The results revealed that the most sensitive bacterial culture was found to be Staphylococcus aureus with the inhibition zone diameter of $15.66 \mathrm{~mm}$ and the MIC value of $0.125 \mathrm{mg} / \mathrm{ml}$, while Escherichia coli was the most resistant bacterial strain with the inhibition zone diameter of 11.66 $\mathrm{mm}$ and the MIC value of $1 \mathrm{mg} / \mathrm{ml}$ [38].

Sesquiterpenes have been shown to exhibit different biological effects such as antibacterial, cytotoxic, and antifungal activities [39-41]. On the other hand, sesquiterpenes such as sesquicineole, spathulenol, $\alpha$-bisabolol, and $\beta$-gurjunene were the main constituents of the essential oil obtained from aerial parts of $E$. pyramidale and accounted for over $59.7 \%$ of the oil (Table 1). Therefore, it can be concluded that the sesquiterpene components are the possible cause of the antibacterial effect of the essential oil of E. pyramidale. Further research is needed to investigate the biological activities of the oil of E. pyramidale.

Table 3. In vitro antibacterial activities of the essential oil of the aerial parts of Eryngium pyramidale.

\begin{tabular}{|c|c|c|c|c|c|c|c|c|c|}
\hline \multirow[b]{2}{*}{ Sample } & \multicolumn{9}{|c|}{ Microorganisms } \\
\hline & $\begin{array}{l}\text { Bacillus } \\
\text { pumilus }\end{array}$ & $\begin{array}{l}\text { Bacillus } \\
\text { subtilis }\end{array}$ & $\begin{array}{c}\text { Staphylococcus } \\
\text { aureus }\end{array}$ & $\begin{array}{c}\text { Bacillus } \\
\text { cereus }\end{array}$ & $\begin{array}{c}\text { Klebsiella } \\
\text { pneumoniae }\end{array}$ & $\begin{array}{l}\text { Enterococcus } \\
\text { faecalis }\end{array}$ & $\begin{array}{l}\text { Escherichia } \\
\text { coli }\end{array}$ & $\begin{array}{l}\text { Staphylococcus } \\
\text { epidermidis }\end{array}$ & $\begin{array}{c}\text { Pseudomonas } \\
\text { aeruginosa }\end{array}$ \\
\hline \multirow{2}{*}{ Essential oil } & $18^{\text {[a] }}$ & 12 & 18 & 12 & 10 & 14 & 17 & 18 & \multirow{2}{*}{ - } \\
\hline & $(7.5)^{[b]}$ & $(>15)$ & $(7.5)$ & (15) & (15) & (15) & $(7.5)$ & $(7.5)$ & \\
\hline \multirow{2}{*}{ Tetracycline $^{[\mathrm{c}]}$} & \multirow{2}{*}{ [nt] } & 21 & 20 & \multirow{2}{*}{ [nt] } & \multirow{2}{*}{ [nt] } & \multirow{2}{*}{ [nt] } & - & 34 & \multirow{2}{*}{ [nt] } \\
\hline & & (3.2) & (3.2) & & & & [nt] & (1.6) & \\
\hline \multirow{2}{*}{ Gentamicin $^{[\mathrm{d}]}$} & \multirow{2}{*}{ [nt] } & - & - & \multirow{2}{*}{ [nt] } & \multirow{2}{*}{ [nt] } & \multirow{2}{*}{ [nt] } & 23 & - & \multirow{2}{*}{ [nt] } \\
\hline & & [nt] & [nt] & & & & (3.2) & [nt] & \\
\hline \multirow{2}{*}{ Ampicillin ${ }^{[e]}$} & 15 & 14 & 13 & \multirow{2}{*}{ [nt] } & \multirow{2}{*}{ [nt] } & \multirow{2}{*}{ [nt] } & 12 & 19 & \multirow{2}{*}{ [nt] } \\
\hline & (15) & (15) & (15) & & & & (15) & (15) & \\
\hline
\end{tabular}

[a]: Zone of inhibition $(\mathrm{mm})$ includes the diameter of the disc $(6 \mathrm{~mm})$, [b]: Minimum inhibitory concentration values as mg.ml ${ }^{-1}$, [-]: Inactive, (7-13): Moderately active, (> 14): Highly active, [nt]: Not tested, [c]: Tested at $30 \mu \mathrm{g} / \mathrm{disc}$, [d]: Tested at $10 \mu \mathrm{g} / \mathrm{disc}$, [e]: Tested at $10 \mu \mathrm{g} / \mathrm{disc}$
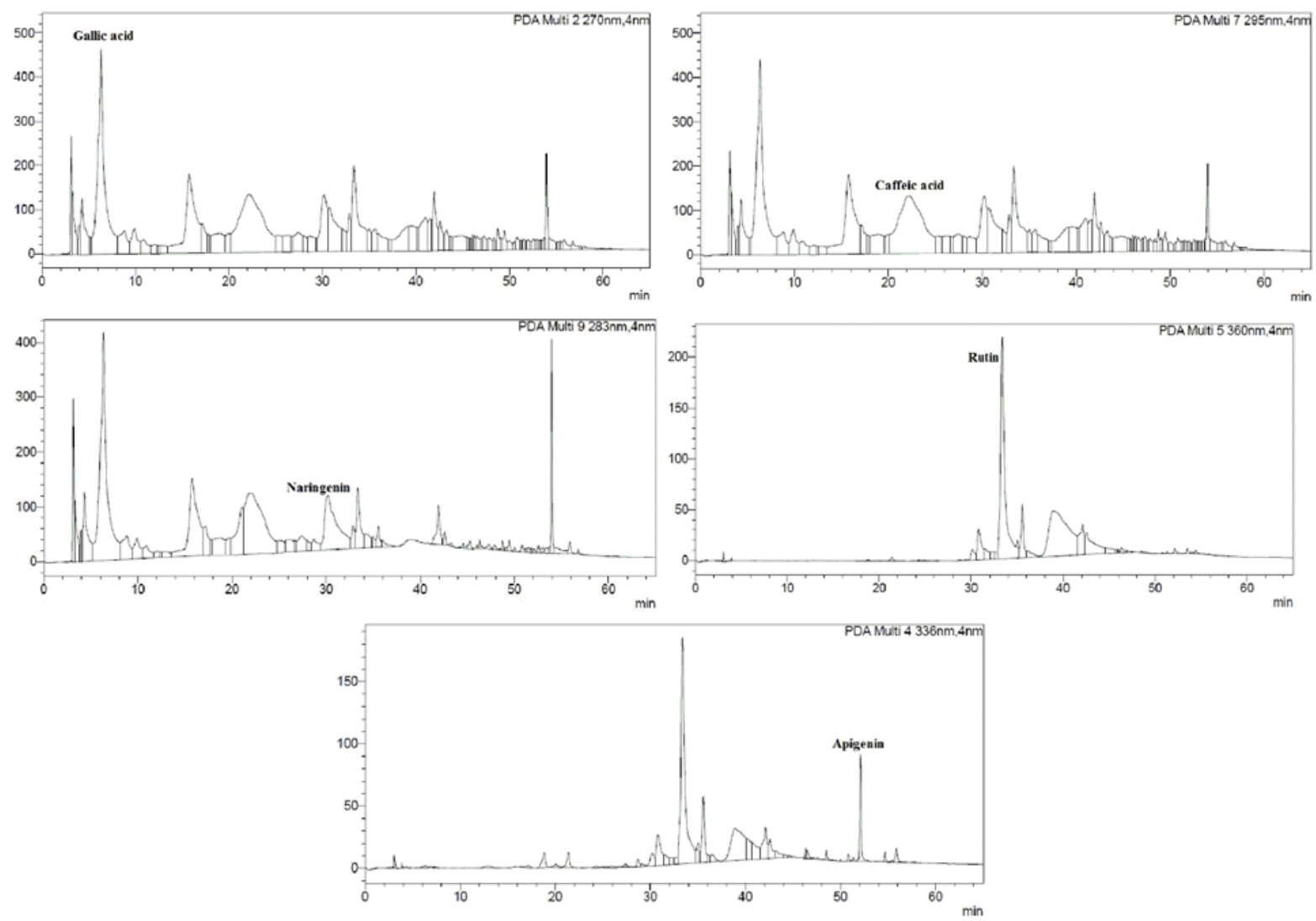

Figure 3. HPLC peaks of gallic acid, caffeic acid, naringenin, rutin, and apigenin in the HPLC chromatogram of the methanolic extract of Eryngium pyramidale. 


\subsection{HPLC analysis}

After the phytochemical analyses indicated the presence of phenolic compounds in the methanolic extract of E. pyramidale; the RP-HPLC-DAD method was used to analyze the methanolic extract to investigate its bioactive compounds, considering its significant total phenolic and flavonoid contents. Among 10 standard compounds used with flavonoid or phenolic structure, five compounds were identified and quantified in the methanolic extract. As shown in Table 4 and Figure 3, these flavonoid and phenolic compounds were naringenin, rutin, apigenin, caffeic acid, and gallic acid with concentrations of $2162.4 \pm 22.2,783.3 \pm 12.2,69.1 \pm 1.1,14.4 \pm 0.9$, and $3.2 \pm 0.04 \mathrm{mg} / 100 \mathrm{~g}$ of the plant, respectively. Also, Figure 2 presents the chemical structures of these bioactive compounds in the methanolic extract.

Table 4. Quantitative results for the determination of phenolic compounds in the methanolic extract of Eryngium pyramidale.

\begin{tabular}{|l|c|c|c|c|c|}
\hline Compounds & $\begin{array}{c}\text { Retention } \\
\text { time (min) }\end{array}$ & $\begin{array}{c}\text { Absorption } \\
\text { maximum } \\
\text { wavelengths (nm) }\end{array}$ & $\begin{array}{c}\text { Amount of } \\
\text { compounds in extract } \\
\text { (mg/100g of plant) }\end{array}$ & $\begin{array}{c}\text { LOD } \\
(\mathbf{n g} / \mathbf{m l})\end{array}$ & $\begin{array}{c}\text { LOQ } \\
(\mathbf{n g} / \mathbf{m l})\end{array}$ \\
\hline Gallic acid & 6 & 270 & $3.2 \pm 0.04^{[\mathrm{a}]}$ & 500 & 1000 \\
\hline Caffeic acid & 22 & 295 & $14.4 \pm 0.9$ & 50 & 100 \\
\hline Naringenin & 30 & 283 & $2162.4 \pm 22.2$ & 50 & 200 \\
\hline Rutin & 34 & 360 & $783.3 \pm 12.2$ & 20 & 50 \\
\hline Apigenin & 52 & 336 & $69.1 \pm 1.1$ & 200 & 500 \\
\hline
\end{tabular}

[a]: Values expressed are mean \pm standard deviation of the mean $( \pm \mathrm{SD})$ of three replications

Among the identified flavonoid and phenolic compounds in the methanolic extract, naringenin was found to be the most abundant compound in the methanolic extract $(2162.4 \pm 22.2 \mathrm{mg} / 100 \mathrm{~g}$ of the plant). Naringenin $(2,3$ dihydro-5,7-dihydroxy-2-(4-hydroxyphenyl)-4H-1-benzopyran-4-one) is a naturally occurring flavonoid belonging to the flavanones. This metabolite is mostly found in citrus fruits, vegetables, and tomato and produces several pharmacological effects on human health such as antibacterial, anticancer, antiviral, anti-mutagenic, antitumor, anti-inflammatory, antihypertensive, antioxidant, antiproliferative, anti-atherogenic, and anti-estrogenic activities, which cause this flavonoid to be applied in cosmetic, perfumery, and various pharmaceutical formulations [42-44]. Rutin is another flavonoid found in the methanolic extract that has been shown to have different pharmacological effects including antioxidant, anticarcinogenic, vasoprotective, neuroprotective, cytoprotective, and cardioprotective activities [45]. Moreover, apigenin as a natural bioactive flavonoid exhibits antioxidant, anti-inflammatory, and anticancer activities [46, 47]. On the other hand, caffeic acid (3,4dihydroxycinnamic acid) derivatives, mainly chlorogenic acid and rosmarinic acid, are the main phenolic acids in the genus Eryngium [48]. Furthermore, the potent antioxidant activity of caffeic acid has been proven [49]. As a naturally occurring plant phenol, gallic acid possesses antimutagenic, pro-oxidant, anticarcinogenic, antioxidant, and anti-inflammatory properties $[50,51]$. Regarding the beneficial effects of flavonoid and phenolic compounds on human health and the presence of these secondary metabolites in the methanolic extract of Eryngium pyramidale, this extract can be considered to use in the pharmaceutical, food, and cosmetic productions.

\section{CONCLUSION}

This work aimed to investigate the chemical compositions and biological activity of Eryngium pyramidale. The findings indicated that oxygenated sesquiterpenes such as sesquicineole, spathulenol, $\alpha$-bisabolol, and $\beta$-gurjunene were the main components of the essential oil of this plant; and the plant extract was a rich source of bioactive phenolic and flavonoid compounds such as naringenin, rutin, apigenin, caffeic acid, and gallic acid. Moreover, E. pyramidale indicated significant antibacterial effects. Since various biological activities have been reported for these bioactive compounds in previous studies, this plant can be considered as a potential candidate in the cosmetic, food, and pharmaceutical productions. Future research should consider the potential effects of the essential oil and extract of this plant more carefully.

\section{CONFLICT OF INTEREST}

The authors declare that there are no conflicts of interest in this investigation.

\section{ACKNOWLEDGMENTS}

This study was supported by Islamic Azad University, Central Tehran Branch (IAUCTB). The authors also wish to express their thanks to the Vice-chancellor for Research and Technology, Hamadan University of Medical Sciences for the help during the study.

\section{REFERENCES}

1. A. Medbouhi, F. Benbelaïd, N. Djabou, C. Beaufay, M. Bendahou, J. QuetinLeclercq, A. Tintaru, J. Costa, A. Muselli, Molecules. 24, 14, (2019).

2. H. Mejri, M. Tir, A. Feriani, L. Ghazouani, M. S. Allagui, M. Saidani-Tounsi, J Funct Foods. 37, (2017).

3. C. I. Calvino, S. G. Martínez, S. R. Downie, Mol. Phylogenet. Evol. 46, 3 , (2008).

4. D. B. Lucas, I. I. Boldrini, Syst. Bot. 43, 3, (2018)

5. M. G. Sepanlou, M. M. Ardakani, M. Hajimahmoodi, S. Sadrai, G.-R. Amin N. Sadeghi, S. N. S. Lamardi, Tradit. Med. Res. 4, 3, (2019).

6. M. Rezvani, F. Zaefarian, Acta Bot Brasilica. 31, 2, (2017).

7. M. D. Vukic, N. L. Vukovic, G. T. Djelic, A. Obradovic, M. M. Kacaniova, S. Markovic, S. Popović, D. Baskić, Ind Crops Prod. 115, (2018).

8. S. M. Razavi, H. R. Vahidipour, A. Ghasemian, G. Imanzadeh, Indian J Nat Prod Resour. 9, 1, (2018)

9. A. Djebara, M. Ciavatta, V. Mathieu, M. Colin, F. Bitam, M. Carbone, M. Gavagnin, Fitoterapia. 138, (2019)

10. J. S. Matejić, Z. Z. Stojanović-Radić, M. S. Ristić, J. B. Veselinović, B. K. Zlatković, P. D. Marin, A. M. Džamić, J. Food Sci. Technol. 55, 8, (2018).

11. N. Ayoub, M. Al-Azizi, W. König, K. H. Kubeczka, Flavour Fragr. J. 21, 6 , (2006).

12. S. Nacef, H. Ben Jannet, M. Hamza, Z. Mighri, J. Soc. Tun. Chim. 10, 2 (2008).

13. I. Rjeibi, A. B. Saad, S. Ncib, S. Souid, J Coast Life Med. 5, 5, (2017).

14. N. L. Vuković, M. D. Vukić, G. T. Đelić, M. M. Kacaniova, M. Cvijović, Kragujevac J. Sci. 40, (2018).

15. A. Wörz, H. Diekmann, Plant Divers Evol. 128, 3-4, (2010).

16. M. Ayuso, J. Pinela, M. I. Dias, L. Barros, M. Ivanov, R. C. Calhelha, M. Soković, P. Ramil-Rego, M. E. Barreal, P. P. Gallego, Ind Crops Prod. 148, (2020).

17. S. E. Aleksandrovna, E. L. Mikhailovna, K. D. Alexeevich, Pharmacogn. J. 10, 6s, (2018)

18. B. Muckensturm, A. Boulanger, M. Farahi, J. Reduron, Nat. Prod. Res. 24 , 5, (2010).

19. Z. Zhang, S. Li, S. Ownby, P. Wang, W. Yuan, W. Zhang, R. S. Beasley, Phytochemistry. 69, 10, (2008).

20. S. Nacef, M. Msaddek, H. Ben Jannet, S. Attia, J. Chriaa, A. Bakhrouf, Z Mighri, J. Soc. Alger. Chim. 13, (2003).

21. B. Soumia, Eryngium campestre L.: Polyphenolic and Flavonoid Compounds; Applications to Health and Disease, in Polyphenols: Mechanisms of Action in Human Health and Disease, Elsevier, 2018; p. 6979.

22. S. A. Erdem, S. F. Nabavi, I. E. Orhan, M. Daglia, M. Izadi, S. M. Nabavi, DARU J. Pharm. Sci. 23, 1, (2015).

23. A. R. Fallahzadeh, M. Zarei, S. Mohammadi, Entomology and Applied Science Letters. 3, 5, (2016).

24. H. Van den Dool, P. D. Kratz, A generalization of the retention index system including linear temperature programmed gas-liquid partition chromatography. 1963; p.

25. R. P. Adams, Identification of essential oil components by gas chromatography/mass spectrometry, Allured Publishing Corp., Carol Stream IL, 2007.

26. P. Khatri, J. Rana, P. Jamdagni, A. Sindhu, Int. J. Res. 5, 2, (2017).

27. H. O. Edeoga, D. Okwu, B. Mbaebie, Afr. J. Biotechnol. 4, 7, (2005)

28. T. Kerdar, N. Rabienejad, Y. Alikhani, S. Moradkhani, D. Dastan, J. Ethnopharmacol. 239, (2019).

29. E. Baron, S. Finegold, Diagnostic microbiology: part 2. Method for testing antimicrobial effectiveness. Berlin, Germany: Springer.[Google Scholar] $1991 ; \mathrm{p}$.

30. J. Palá-Paúl, L. M. Copeland, J. J. Brophy, R. J. Goldsack, Biochem. Syst. Ecol. 34, 11, (2006).

31. N. M. Al-Abd, Z. M. Nor, M. Mansor, A. Zajmi, M. S. Hasan, F. Azhar, M. Kassim, Asian Pac. J. Trop. Biomed. 7, 6, (2017).

32. H. I. Al-Jaber, Jordan J Chem. 12, (2017). 
33. M. B. Bahadori, L. Dinparast, G. Zengin, C. Sarikurkcu, S. Bahadori, B. Asghari, N. Movahhedin, Int. J. Food Prop. 20, 8, (2017).

34. S. Aryal, M. K. Baniya, K. Danekhu, P. Kunwar, R. Gurung, N. Koirala, Plants. 8, 4, (2019).

35. S. Zeidan, A. Hijazi, H. Rammal, A. Al Bazzal, H. Annan, A. Al-Rekaby, Eu Chem Bul. 4, 11, (2015).

36. L. Paşayeva, E. K. Şafak, T. Arıgün, H. Fatullayev, O. Tugay, J Pharm Pharmacogn Res. 8, 1, (2020).

37. D. Merghache, Z. Boucherit-Otmani, S. Merghache, I. Chikhi, C. Selles, K. Boucherit, Nat. Prod. Res. 28, 11, (2014).

38. S. S. Mirahmadi, M. Aminzare, H. H. Azar, K. Kamali, J. Food Saf. 40, 2, (2020).

39. N. K. T. Dharmayani, T. Yoshimura, E. Hermawati, L. D. Juliawaty, Y. M. Syah, Z. Naturforsch. C. 75, 1-2, (2020).

40. M. Wang, L. Zhao, K. Chen, Y. Shang, J. Wu, X. Guo, Y. Chen, H. Liu, H. Tan, S.-X. Qiu, Bioorg. Chem. 96, (2020).

41. W. Fang, J. Wang, J. Wang, L. Shi, K. Li, X. Lin, Y. Min, B. Yang, L. Tang, Y. Liu, J. Nat. Prod. 81, 6, (2018).
42. B. Salehi, P. V. T. Fokou, M. Sharifi-Rad, P. Zucca, R. Pezzani, N. Martins, J. Sharifi-Rad, Pharmaceuticals. 12, 1, (2019).

43. P. Venkateswara Rao, S. Kiran, P. Rohini, P. Bhagyasree, J. Pharmacogn. Phytochem. 6, (2017).

44. A. Semalty, M. Semalty, D. Singh, M. Rawat, J Incl Phenom Macrocycl Chem. 67, 3-4, (2010).

45. A. Ganeshpurkar, A. K. Saluja, Saudi Pharm J. 25, 2, (2017).

46. S. Shukla, S. Gupta, Pharm. Res. 27, 6, (2010).

47. J. Madunić, I. V. Madunić, G. Gajski, J. Popić, V. Garaj-Vrhovac, Cancer Lett. 413, (2018).

48. M. Kikowska, J. Długaszewska, M. M. Kubicka, I. Kędziora, J. Budzianowski, B. Thiem, Herba Pol. 62, 2, (2016).

49. İ. Gülçin, Toxicology. 217, 2-3, (2006).

50. S. Shahrzad, K. Aoyagi, A. Winter, A. Koyama, I. Bitsch, J. Nutr. 131, 4, (2001).

51. B. Badhani, N. Sharma, R. Kakkar, RSC Adv. 5, 35, (2015). 